\title{
TRADUÇÃO \\ Uma fonte histórica do perspectivismo de Nietzsche: $G$. Teichmüller, o mundo real e o mundo aparente ${ }^{1}$
}

Hermann Nohl (Jena)

Nietzsche sempre se opôs tão apaixonadamente ao mero pensar reativo, o pensar por ocasião do que outras pessoas pensaram, e suas frases parecem fluir tão livremente de vivências imediatas, que é decepcionante se perceber pensando nele agora via observações sofisticadas e restrito contexto histórico de um trabalho erudito. Mesmo quando se sabe que o "vivido e sofrido pessoalmente" caso um artifício consciente, e que a realidade mesmo para o mais "livre" dos homens nunca é simplesmente "a vida", mas sempre a formação dessa vida alcançada até então, como para o pintor é o campo de imagens de seus predecessores, para o filósofo é o trabalho conceitual. Mas os historiadores praticamente renunciaram até agora a vingança de pôr à prova o poder desprezado também com relação a esse grande inimigo, por algum tipo de sentimento de beleza que se pode sentir em todos os escritos sobre Nietzsche. E, ainda assim, tal comprovação, de que mesmo para ele muitas vezes apenas um livro vale como fonte de ideias e em que contexto de natureza histórica seus pensamentos se formaram, tem um significado positivo tanto para a compreensão quanto para a crítica de seus escritos.

Em primeiro lugar, de modo puramente superficial. Repetidas vezes leitores atentos deparar-se-ão com trechos, por assim dizer, eventuais, e que se baseiam em pressupostos de pensamento completamente diversos, que poderiam torná-

\footnotetext{
1 Nohl, H. (1912). Eine historische Quelle zu Nietzsches Perspektivismus: G. Teichmüller, die wirkliche und die scheinbare Welt. Sonder-Abdruck aus der Zeitschrift für Philosophie und philosophische Kritik.Herausgegebenvon Hermann Schwarz, Bd. 149. Leipzig: Johann Ambrosieus Barth, 1912. Tradução de Ricardo Bazilio Dalla Vecchia (professor da Faculdade de Filosofia e do Programa de Pós-Graduação em Filosofia da Universidade Federal de Goiás). Revisão técnica de Erik Petschelies.

2 Para facilitar a identificação das citações, apresentarei a sua referência de acordo com a posterior edição de Colli e Montinari (KSA): Nietzsche, F. (1988). Sämtliche Werke. Kritische Studienausgabe. Berlin/New York: de Gruyter, 15v. Embora não faça a devida citação dos trechos entre aspas, tampouco declare qual edição utilizou, neste mesmo ensaio Nohl menciona o volume XVI da "nova edição" de Otto Weiss, isto é, a Gesamtausgabe (GOA), publicada pela editora Naumann entre 1899 e 1904. No presente caso, trata-se do apontamento 9 [115] de 1887. KSA 12, 400. (Nota do Tradutor).
} 
los desconfiados com relação à honestidade intelectual de Nietzsche. Tais trechos inverídicos vão se manifestar, por ocasião de uma observação mais atenta, precisamente enquanto noções e anotações eruditas e apenas será possível interpretá-los de forma justa quando se conhece a loja em que eles foram comprados, ou o estrangeiro para quem vale o aceno e em cuja língua se fala a respeito disso.

Tal papel instigador desempenhou, em um grau surpreendente em para Além do bem e do mal e depois para a Vontade de poder, o livro de Gustav Teichmüller, O mundo real e o mundo aparente (Breslau, 1882), e uma investigação de seu efeito sobre os últimos escritos de Nietzsche ajudará a entender algumas fórmulas incompreensíveis. Com efeito, causará espanto a facilidade com que às vezes os pensamentos se arranjam. Um drástico exemplo disso é o aforismo 20 de Além do bem e do mal, onde se menciona o parentesco inato e sistemático dos conceitos filosóficos e onde Nietzsche com um gesto consciente desfecha: "Isto como resposta à superficialidade de Locke no tocante à origem das ideias". ${ }^{3}$ Deve-se achar esse gesto final algo esquisito, quando se percebe que esse aforismo nada mais é do que uma ligeira releitura das frases das páginas 14 e 15 de Teichmüller, onde ele apresenta a sua doutrina platônica do Syndesmos dos conceitos. Especialmente a sugestão de Nietzsche, de reduzir à dependência da linguagem a relação entre os conceitos que sempre compelem aos mesmos caminhos do conhecimento, brotou do questionamento de Teichmüller, o qual, ainda que em sentido completamente diferente, exigiu que a soberania do pensamento se fizesse independente da coerção da linguagem. Assim se prepara uma poção deste insight (Aperçus) a partir de ingredientes estrangeiros.

Algo mais importante, no entanto, do que a investigação do efeito do livro de Teichmüller sobre Nietzsche também pode ser visto em um nível mais profundo do seu trabalho, do qual surgiu o seu novo pragmatismo, o Perspectivismo, a doutrina do mundo aparente por trás do qual não há real - ou como se queira denominar essa teoria biológica do conhecimento com suas críticas dos conceitos fixos em benefício do devir criador. Pode-se com toda certeza dizer que este trabalho realizou-se única e exclusivamente em discussão com este livro.

Teichmüller, como tantos de nossos melhores pensadores alemães, emergiu da escola de Trendelenburg, como Dilthey, Eucken ou Brentano. Ele é absoluta e injustamente esquecido hoje, pois não apenas é um dos poucos que na metade do século passado tinham uma personalidade filosófica e um estilo filosófico próprios, de modo que ainda hoje se pode aprender algo com ele, e em alguns pontos ele era um homem original, com toda a presunção e sangue frio que the era peculiar, áspero como um hegeliano, mas bastante diferente, informal e bem humorado, ele

3 Para a citação das obras publicadas de Nietzsche em português utilizaremos a tradução de Paulo César de Souza, da editora Companhia das Letras. A tradução dos fragmentos póstumos é de minha autoria. (Nota do Tradutor) 
Uma fonte histórica do perspectivismo de Nietzsche: G. Teichmüller...

impor-se-ia a pensamentos modernos. ${ }^{4}$ Muitas conexões nas partes mais difíceis da história da filosofia moderna podem ser compreendidas mais claramente quando se o conhece e o compara com Brentano. Como alunos de Trendelenburg, ambos partem das pesquisas aristotélicas a que Teichmüller por paixão própria acrescentou algo platônico e que também agiram sobre Lotze. A partir de Trendelenburg e Aristóteles, o trabalho de Teichmüller e Brentano (assim como Eucken, originalmente) seguem em direção à história conceitual, e a "diferenciação de significado" daquela doutrina permanece sendo um momento essencial do seu método filosófico, tal como Teichmüller, que dedicou a sua obra principal à determinação e fundamentação dos diferentes conceitos de ser, com o que Brentano começou. Ambos são levados a partir de Aristóteles para uma psicologia descritiva, num caminho muito diferente de Dilthey, para quem, assim como Nietzsche, à luz do romantismo, trata-se inicialmente menos da distinção das funções psíquicas do que do conteúdo psíquico. Há em comum entre eles finalmente certo desprezo por Kant, só que Brentano encontra o tipo de reação mística onde Teichmüller enxerga o cético positivista. Pois assim, Teichmüller, ao retornar para a dialética de Platão justamente ao lado de Lotze, assume uma posição completamente diferente frente ao "plebeísmo dos sentidos", assim como à superstição em relação à moderna filosofia dos cientistas naturais.

No décimo aforismo de Além do Bem e do Mal, Nietzsche, sem citar o seu nome, ofereceu-lhe um memorial, que aqui se lê em suas frases principais:

o afã e a sutileza, quase diria: a astúcia, com que em toda parte da Europa é hoje abordado o problema do "mundo real e do mundo aparente", leva a pensar e a espreitar; e quem aqui nada ouve no fundo, a não ser uma "vontade de verdade", certamente não goza da melhor audição.

Em certos casos pode ser que realmente intervenha uma vontade de verdade:

Entre os pensadores mais fortes, mais vitais, ainda sedentos de vida, as coisas parecem ser diferentes: ao tomar partido contra a aparência e pronunciar já com altivez a palavra "perspectiva", ao conceder ao próprio corpo tão pouco crédito quanto à evidência visual que diz "a terra está parada", deixando assim escapar entre as mãos, com aparente bom humor, a sua posse mais segura ${ }^{5}$, quem sabe se no fundo não querem reconquistar algo que outrora se possuía mais firmemente, algo do velho patrimônio da fé de antigamente, talvez "a alma imortal", talvez "o velho Deus", em suma, ideias com as quais se podia viver melhor, de maneira mais vigorosa e serena, do que com as "ideias modernas"? Nisso há desconfiança frente às ideias modernas, há descrença de tudo o que foi construído ontem e hoje; há talvez, mesclado com isso, um leve desgosto e desdém que não mais suporta o bric-à-brac de conceitos da mais diversa procedência, com que hoje o chamado positivismo se apresenta no mercado,

\footnotetext{
4 Para a minha grande alegria, $\mathrm{K}$. Oesterreich apontou recentemente em favor dessa psicologia do ego, e eu estaria muito enganado se também Frischeisen-Köhler em seu livro Wissenschaft und Wirklichkeit não tivesse bastante a agradecer à sua estimulante influência.

5 Nohl subtrai um pequeno trecho entre parênteses nesta frase, a saber: “... a sua posse mais segura (pois em que se acredita mais firmemente agora do que no corpo?), quem sabe..." (Nota do Tradutor).
} 
uma náusea do gosto mais exigente face ao colorido de feira e aspecto andrajoso desses filosofrastros da realidade, nos quais nada há de novo e autêntico, exceto o colorido. Nisso me parece que devemos dar razão aos atuais céticos antirrealistas e microcopistas do conhecimento: o instinto que os leva a se afastar da realidade moderna não está refutado - que nos interessam suas vias retrógradas e tortuosas! 0 essencial neles não é que desejem ir para trás, mas que desejem ir embora. Um pouco mais de força, impulso, ânimo, senso artístico: e desejariam ir para além - não para trás -.

Que estas frases realmente se aplicam a Teichmüller prova o já referido título de sua obra, assim como a sua palavra preferida "perspectivístico" - ambas colocadas entre aspas pelo próprio Nietzsche. De modo geral, quase todos os 23 aforismos deste primeiro capítulo, e também o aforismo 34 do segundo capítulo, foram escritos em estreita relação com este livro. O primeiro capítulo trata “dos preconceitos dos filósofos" e o representante dos filósofos, de quem Nietzsche deduziu esses preconceitos, é justamente Teichmüller. Através desta constatação, a contrapartida, em relação à qual Nietzsche se orienta, é tornada bem mais concreta. Mas a polêmica não foi simplesmente tão negativa. Quem tiver ouvidos mais refinados vai deduzir isso da adoção da palavra-chave ótica-de-perspectiva da vida (por exemplo, no aforismo 2). ${ }^{6}$ No entanto, isto apenas fica mais claro na parte epistemológica da vontade de poder, que está totalmente afinada com o livro de Teichmüller (sessão 260-295 na antiga numeração, na nova edição de O. Weiss, volume XVI, p. 3-103). ${ }^{7}$ Nesta nova versão da vontade de poder, a influência deste debate também será bastante perceptível em outros lugares, por exemplo, logo no início, volume XV, páginas 151,153 , onde a terminologia "Resultados de determinadas perspectivas de utilidade, apenas falsamente projetadas na essência das coisas"» ou "uma aparência perspectivística cuja origem está em nós mesmos"9 é terminologia de Teichmüller.

Eu menciono rapidamente as características determinantes do "mundo real e do aparente" que eram de importância para Nietzsche; os resultados mais profundos e a verdadeira força do livro não são esgotadas desta maneira, elas apenas não estão em questão para Nietzsche. Teichmüller inicia com uma distinção de significado dos diferentes conceitos de ser, que ele caracteriza como ser dos conteúdos da consciência $=$ ser ideal $=0$ que, como ser de atividade $=$ ser real $=$ o que e enquanto ser do sujeito $=$ ser substancial. Todos os sistemas filosóficos até agora resultam em razão dessa distinção, como representações projetivas do conteúdo do nosso conhecimento, que enquanto tal tem apenas um ser ideal. Nenhum dos sistemas

\footnotetext{
6 Nohl transcreve a expressão "Perspektivenoptik des Lebens", porém ela não pertence ao aforismo 02, mas ao aforismo 11 de Além do bem e mal. (Nota do tradutor)

7 Após o índice no Volume XV, o Volume XVI ainda não estava disponível para mim. Espero que nem todo novo editor traga uma nova variação, o material parece ser causa disto.

8 KSA 13, 49 (Nota do tradutor).

9 KSA 12, 354 (Nota do tradutor).
} 
encontrou então o ser substancial, eles buscam em vão o sujeito em seus conteúdos ideais. Como o conhecimento necessariamente está relacionado com o ponto de vista do sujeito, então todos esses sistemas são meras imagens perspectivas. Conceitos, que expressam o sujeito, são projetados para fora, este é o erro do dogmatismo, e não, como pensa Kant, que com seus conceitos ele exceda os poderes da cognição. Assim se está livre do círculo mágico perspectivístico desses sistemas. Ao lado do conceito de "perspectivístico", Teichmüller ainda introduziu o de "conhecimento semiótico". A dificuldade de um eu poder conhecer um não-eu dissolve-se ao se manifestar como superstição o velho ponto de partida, de que não se conhece nada que não seja propriamente conhecimento. Interpretamos a desconhecida vida psíquica por meio de signos, mas os próprios estados somente são perceptíveis semioticamente, pois querer não é conhecimento. Temos uma consciência de funções desconhecidas, cujo conteúdo pode ser expresso semioticamente pelo conteúdo do conhecimento. Mesmo o conceito de eu "sujeito-objeto" é meramente semiótico para o verdadeiro sujeito, pois o eu não é apenas cognoscente, mas também senciente e agente. Portanto, temos consciência do eu, mas nenhum saber, uma distinção através da qual "todo idealismo desde Platão é comprometido". Semiótico é também o conhecimento da ciência da natureza. A pretensa ciência da realidade dá apenas uma fórmula útil para a expressão semiótica das leis dos fenômenos, mas não dá o menor conhecimento das coisas reais e dos eventos reais. A verdadeira substância é o sujeito e a verdadeira interpretação é, por analogia, o nosso eu.

Essa demonstração da aparência do mundo da ciência natural, reivindicado como o mundo da realidade, como no poema de Parmênides, preenche a segunda parte do livro. Tudo aqui é perspectivístico, como a compreensão do mundo está determinada pela estrela a partir da qual ele é visto.

O rato lamenta quando é atacado pelo gato; o gato está muito satisfeito com isso. Se o Partido Progressista exalta uma lei, então os conservadores ficam cabisbaixos e vice-versa. Em suma, a percepção das coisas está sempre relacionada a determinado ponto de vista e é, portanto, perspectivística. ${ }^{10}$

Mas também não existem as "coisas reais, cuja relação com o sujeito é apreendida, mas, ao invés disso, apenas podemos tomar como objeto a multiplicidade das próprias sensações e explicar a síntese pelo sujeito para o quadro de perspectiva”. Daqui se extraem graves consequências. Disso resulta, então, que as formas das intuições, nas quais unimos as sensações nas assim chamadas intuições, constituem o caráter perspectivista da imagem, e consequentemente não têm nada a ver com a realidade.

10 Nohl cita, mais uma vez sem a devida referência, a introdução de Die wirkliche und die scheinbare Welt. Cf.: Teichmüller (1882, p. 185).Para a conferência das citações de Teichmüller consultamos a cópia digital do original disponível em: $<$ https://archive.org/details/diewirklicheund00teicgoog/page/n359>. (Nota do tradutor) 
Coisa, espaço, tempo, movimento tem apenas um significado perspectivista. As ciências naturais empíricas, que reduzem tudo a espaço e movimento, são apenas uma grandiosa semiótica realizada. A respeito desta realização, que é muito interessante em alguns casos, não se pode detalhar aqui. Apenas um exemplo pode ser apresentado. Trata-se da questão por que nesta semiótica imagem de mundo as representações visuais e táteis são tão predominantes? Teichmüller responde:

0 que domina exerce sempre em qualquer sociedade o elemento mais forte. Seja a força proveniente da mera preponderância em números, como muitos corvos superam mesmo o falcão, ou da preponderância de um elemento construído na sociedade, como a riqueza, a fé (em um sentido passivo), ou a sabedoria e força de vontade. 0 elemento que chegou ao domínio vai necessariamente subjugar com o tempo toda a sociedade aos seus pontos de vista, sentimentos, desejos e costumes e a lei válida será sempre a expressão das formas de vida dadas no elemento dominante. Mas, sem dúvida, é o sentido da visão que oferece o elemento mais forte e mais numeroso na sociedade das representações sensíveis, que constituem o mundo dos sentidos. A partir disso um político experiente profetizaria de antemão que a visão logo ganharia autoridade incondicional e que as formas próprias à visão se imporiam também sem ação da legislação, infalivelmente, em todo o território do mundo dos sentidos. Nenhuma ciência empírica jamais se atreveu a imaginar outras formas de constituição da organização política do mundo dos sentidos, por exemplo, a do ouvido e a do olfato. E a filosofia? Ela foi pelo mesmo caminho. ${ }^{11}$

Ela permitiu que a necessidade dessas formas se the impusesse, mesmo ali, onde ela afirmou-a como mera forma da aparência, sem ter encontrado a razão do seu domínio geral em sua força, que se impõe em sua organização política e social de nossas mais diversas sensações. Se à humanidade permanecesse negado o sentido do tato e da visão, então o mundo dos sentidos teria sido posto pela ciência empírica sob formas da percepção alheias a espaço, corporeidade e matéria. Em Nietzsche, a música soa muito diferente, mas qualquer um reconhecerá facilmente os seus meios decisivos. Não apenas a terminologia "perspectivístico", "projetar semioticamente" e, sobretudo, a recorrente oposição do "mundo real ou verdadeiro e do mundo aparente", mas também a percepção de que a formação de conceitos das ciências naturais é meramente semiótica, porém útil, a libertação da superstição metafísica do atomismo etc. Finalmente, a dissolução deste mundo no devir incognoscível. Um exemplo muito claro disso é a sessão 275 da "Vontade". ${ }^{12}$ O mundo dos fenômenos é o mundo enfeitado.

O oposto deste mundo fenomenal não é o mundo verdadeiro, mas o mundo sem forma e informulável do caos das sensações - em outras palavras, outro tipo de mundo

11 Teichmüller (1882, p. 322). (Nota do tradutor).

12 KSA 12, 395. Nohl faz referência à "obra" Vontade [de Poder].Como se sabe, esta "obra" é o produto de uma fraude editorial produzida pela irmã de Nietzsche, Elisabeth Föster Nietzsche. Sobre isso, cf.: Montinari, M. (1996). "La volonté de puissance" n'existe pas. Choix d'articles établi et postfacé par Paolo D' lorio, traduit de l'italien par Patricia Farazzi et Michel Valensi. Paris, Éditions de l'éclat (Nota do Tradutor). 
fenomenal, que é irreconhecível para nós. As questões sobre como as coisas podem ser em si mesmas, independentemente de nossa receptividade pelos sentidos e da atividade do entendimento, devem ser rebatidas com a pergunta: como podemos saber que as coisas existem? A coisidade apenas foi criada por nós. A questão é se não haveria muitas outras espécies que criam tal mundo aparente. Se não é o caso de ser real tão só aquilo que postula a coisa, e se não é o caso do efeito do mundo exterior sobre nós ser apenas consequência de tais sujeitos volitivos. Apenas o sujeito é demonstrável; hipótese de que existam apenas sujeitos -.

Aqui se dá, contudo - onde ele parece estar completamente preso a Teichmüller - também o afastamento. Ele rejeita o conceito de eu, o conceito de sujeito, no qual Teichmüller havia encontrado o seu fundamento sólido. 0 eu é um dos "Preconceitos dos filósofos" em Além do bem e mal. Na sessão 273 da Vontade de Poder, consta:

O conceito de substância, uma consequência do conceito de sujeito: não o inverso! (Esta foi a sentença de Teichmüller). Se renunciamos à alma, ao sujeito, falta o pressuposto para uma substância em geral. Obtém-se graus de entes, se perde o ente. Sujeito: eis a terminologia de nossa crença na unidade por baixo de todos os diferentes momentos de maior sentimento de realidade. ${ }^{13}$

Também o mundo interior é fenomenal, aparente. A oposição entre mundo real e aparente é apenas gradual, há apenas um mundo aparente (compare-se especialmente a sessão 293-295 da antiga numeração com os títulos "Crítica dos conceitos”, "Mundo real e aparente", "a aparência” e "novamente o mundo real e aparente”). ${ }^{14}$ Uma segunda oposição, que também aparece em Além do bem e mal, é a rejeição da dialética abstrata e do conceito de um conhecimento intuitivo das ideias, a razão é sensualizada, por exemplo, na sessão 278 da "Vontade [de Poder]", ou na 266: "Sobre esta aparência fundamentamos nossa representação do espírito, da razão, da lógica etc. (- tudo isto não existe: são sínteses e unidades fingidas) e estas nós projetamos de novo nas coisas, por trás das coisas!”. ${ }^{15}$

Assim Teichmüller é superado e seus postulados são dissolvidos com os seus próprios meios. Com qual direito isto acontece, é algo que não precisamos investigar aqui, o que só poderia ocorrer no contexto de uma apresentação da inteira formação do pensamento de Nietzsche. Ela também poderia perseguir detalhadamente esta nota histórica em seu significado para a última fase da filosofia nietzschiana, mas teria nisso também um recurso para observar atentamente a audácia habilidosa deste pensamento com seus fantásticos saltos e precipitações de uma maneira até agora inesperada. A vontade positiva de Nietzsche, que o coloca de modo singular ao lado do novo pragmatismo e ao lado de Bergson, não lhe é contestada por isto. Entretanto, aqui se revela, como naqueles outros, que a nova coragem desta filosofia, da qual ele era tão orgulhoso, nada mais é do que a boa e velha coragem de todos os idealistas

13 KSA 12, 465 (Nota do tradutor).

14 KSA 13, 24 e KSA 13, 270 (Nota do tradutor).

15 KSA 13, 67 (Nota do tradutor). 
desde os Eleatas, e que sua crítica toma a sua força filosófica da crítica idealista das nossas formas do conhecimento desde Kant. 0 que realmente permanece único a Nietzsche é a profunda transposição desta crítica e desta coragem para o campo da moralidade, dos valores e, sobretudo, para toda a dependência da metafísica religiosa e todos os seus "movimentos retrógrados". ${ }^{16}$

Recebido em: 07.07.2020

Aceito em: 30.11 .2020

16 KSA 2, 456 (Nota do tradutor). 